\title{
A study on histopathological changes in placenta in pre-eclampsia/eclampsia: A case-control study in tertiary care centre, western India
}

\author{
CR Gore ${ }^{1}$, Aditi Pandey ${ }^{2, *}$, Abhinav Shetty ${ }^{3}$, Ruby Rao ${ }^{4}$, Sourabh Paranjape ${ }^{5}$ \\ ${ }^{1}$ Professor, $\mathbf{2 , 3 , 4 , 5}$ Resident Dept. of Pathology, Dr. D. Y. Patil Medical College, Hospital \& Research Centre, Dr. D.Y. Patil \\ Vidyapeeth, Pimpri, Pune, Maharashtra, India
}

*Corresponding Author:

Email: draditipandey@gmail.com

Received: $12^{\text {th }}$ January, 2018

Accepted: $10^{\text {th }}$ March, 2018

\begin{abstract}
Introduction: In pregnancy induced hypertension $(\mathrm{PIH})$, pathological changes in the placenta occurs which may result in reduced blood flow across placenta. The present study has been undertaken to assess the morphology \& histology of placenta from mothers with PIH and to correlate their findings with those of normal pregnancies.

Materials and Methods: The present study was a case-control study conducted during July 2015 to September 2017. Placenta of cases of singleton normal pregnancies \& those complicated by pre-eclampsia/ eclampsia and of known gestational period were included. The placentae were divided into two groups; Group 1: Pregnancy with hypertension (cases) and Group 2: Normal pregnancy (control). Detailed macroscopic and microscopic examinations were conducted on the placentae.

Results: The mean weight of placenta (474 \pm 58 grams) was higher among control group in comparison to PIH group (420 \pm 61 grams). This difference was statistically significant. (p 0.001) The mean fetoplacental weight ratio $(6.14 \pm 0.503)$ was higher among PIH group in comparison to control group $(6.03 \pm 0.409)$. This difference was statistically insignificant. $(\mathrm{p}<0.05)$. There was significant association between presence of gross infarction, calcification, Hyalinised area /10 lpf, medial coat proliferation/ 10 lpf, intervillous hemorrhage, decreased villous vascularity and PIH.

Conclusion: It is concluded that there was statistically significant difference between mean birth weight of the babies and mean placental weight in control group and PIH group. It also revealed striking villous lesions like increased syncytial knots, cytotrophoblastic cell proliferation, villous stromal fibrosis and fibrinoid necrosis in placenta from preeclampsia cases.
\end{abstract}

Keywords: Placenta, Histopathological Changes, Pre-eclampsia, Eclampsia.

\section{Introduction}

Hypertensive disorders complicating pregnancy are common. It forms one of the deadly triad, along with haemorrhage \&infection, which contribute greatly to maternal \&foetal morbidity \& mortality. ${ }^{1}$

In pregnancy induced hypertension (PIH), pathological changes in the placenta such as infarction, calcifications, diffuse placental thrombosis, inflammatory placental vasculopathy and abnormal trophoblastic proliferation occur. It results in reduced blood flow across placenta and uteroplacental insufficiency. ${ }^{2}$

Naeye and Friedman (1979) calculated that $70 \%$ of excess foetal deaths in women with hypertension are due to placental infarcts. It has been recorded that the maternal utero-placental blood flow is decreased in PIH due to maternal vasospasm. It causes indirect constriction of foetal stem arteries. Babies of such mothers are mostly small for date. ${ }^{3}$

Histological findings like cytotrophoblastic cellular proliferation, syncytial knot formation, fibrin plaque formation etc. have been observed in greater amount in hypertensive placentae., ${ }^{4,5}$

Gross pathological changes are commonly seen in placentae of severe preeclampsia. The characteristic placental changes of preeclampsia would be predicted to be those associated with placental ischemia. In consistence with this prediction, the placenta in preeclampsia is small. The gross placental changes with severe preeclampsia and foetal growth retardation are quite similar. ${ }^{6,7}$

In view of this, the study of placenta should provide insight into the pathophysiology of preeclampsia. The present study has been undertaken to assess the morphology \& histology of placenta from mothers with pre-eclampsia/eclampsia and to correlate their findings with those of normal pregnancies.

\section{Materials and Methods}

The present study was a case-control study conducted in the Department of Pathology, Dr. D. Y. Patil Medical College, Hospital and Research Centre, Pimpri, Pune in close association with the Department of Obstetrics and Gynecology at our hospital during July 2015 to September 2017.

Placentae of cases of singleton normal pregnancies $\&$ those complicated by pre-eclampsia/ eclampsia were included in the study. The placentae of pregnancies complicated by other medical disorders like diabetes mellitus etc., multiple pregnancies and preterm pregnancies were excluded.

The placenta received from the Department of Obstetrics and Gynecology was divided into two groups.

Group 1: Pregnancy with Hypertension (cases): Placenta of patients (with B.P. > 140/90 mmHg after 28 
weeks of gestation, with/without edema, and/or proteinuria, and/or convulsion)

Group 2: Normal Pregnancy (control): Placenta of uncomplicated term pregnancies with a gestation between $28 \mathrm{wks}$ and $40 \mathrm{wks}$ with no foetal or maternal complications.

Clinical details of mothers like general condition, pallor, BP, edema, history of previous child birth, past illness were recorded on predesigned questionnaire. The routine investigations were also noted. Weight of the placenta and neonate was noted.

For macroscopic examination, placenta were washed, blood and blood clots were removed. Perfusion of placenta with $10 \%$ formalin through umbilical vessels was followed by immersing the placenta in a jar containing $10 \%$ formalin for 24 hours.

After $24 \mathrm{hrs}$ of fixation in formalin, gross examination of the placentae for presence of any infarction, calcification and retro placental clots was done.
For microscopic examination, sections were stained with haematoxylin and eosin stain. Slides were studied under the compound microscope for study of Placental villi, size of villi, syncitial knot formation, hyalinizatiotion, fibrinoid necrosis, cytotrophoblastic proliferation, Stromal pathology, stromal fibrosis, calcification, hyalinization and intervillous hemorrhage.

\section{Rresult}

The present study included 30 placentae of women with PIH and 30 of normal pregnancy. The mean maternal age of control group was $23.5 \pm 3.85$ years and that of PIH category was $24.8 \pm 2.67$ years. The mean gestational age of control group was $39.13 \pm 1.95$ weeks and that of PIH category was $38.8 \pm 1.12$ weeks. There was no significant association between maternal age, gestational age among control and $\mathrm{PIH}$ group (Table 1$)$. (p value $>0.05)$

Table 1: Maternal age group and gestational age wise distribution of study subjects

\begin{tabular}{|c|c|c|c|c|c|c|}
\hline \multirow[t]{2}{*}{ Age group } & \multicolumn{2}{|c|}{$\begin{array}{c}\text { Control } \\
(\mathbf{n}=30)\end{array}$} & \multicolumn{2}{|c|}{$\begin{array}{c}\text { PIH } \\
(\mathbf{n}=\mathbf{3 0})\end{array}$} & \multicolumn{2}{|c|}{$\begin{array}{c}\text { Total } \\
(\mathrm{n}=60)\end{array}$} \\
\hline & No. & $\%$ & No. & $\%$ & No. & $\%$ \\
\hline 20 and below & 8 & 26.7 & 2 & 6.7 & 10 & 16.7 \\
\hline $21-25$ & 15 & 50 & 16 & 53.3 & 31 & 51.7 \\
\hline $26-30$ & 5 & 16.6 & 11 & 36.7 & 16 & 26.6 \\
\hline $31-35$ & 2 & 6.7 & 1 & 3.3 & 3 & 5.0 \\
\hline Total & 30 & 100 & 30 & 100 & 60 & 100 \\
\hline \multirow{2}{*}{$\begin{array}{l}\text { Gestational } \\
\text { age (weeks) }\end{array}$} & \multicolumn{2}{|c|}{$\begin{array}{c}\text { Control } \\
(\mathbf{n}=30)\end{array}$} & \multicolumn{2}{|c|}{$\begin{array}{c}\text { PIH } \\
(\mathbf{n}=30)\end{array}$} & \multicolumn{2}{|c|}{$\begin{array}{c}\text { Total } \\
(n=60)\end{array}$} \\
\hline & No. & $\%$ & No. & $\%$ & No. & $\%$ \\
\hline 37 & 2 & 6.7 & 4 & 13.3 & 6 & 10 \\
\hline 38 & 9 & 30 & 8 & 26.7 & 17 & 28.3 \\
\hline 39 & 6 & 20 & 10 & 33.3 & 16 & 26.7 \\
\hline 40 & 9 & 30 & 6 & 20.0 & 15 & 25 \\
\hline 41 & 4 & 13.3 & 2 & 6.7 & 6 & 10 \\
\hline Total & 30 & 100 & 30 & 100 & 60 & 100 \\
\hline
\end{tabular}

Table 2: Mean of birth weight, placental weight and feto-placental weight ratio

\begin{tabular}{|l|c|c|c|}
\hline & $\begin{array}{c}\text { Control } \\
(\mathbf{n = 3 0 )}\end{array}$ & $\begin{array}{c}\text { PIH } \\
(\mathbf{n = 3 0})\end{array}$ & P value \\
\hline Mean birth weight (gms) & 2853 & 2516 & 0.003 \\
\hline Mean placental weight (gms) & 474 & 420 & 0.001 \\
\hline Mean fetoplacental weight ratio & 6.03 & 6.14 & 0.47 \\
\hline
\end{tabular}

The mean of birth weight, placental weight and fetopalcental ratio was as shown in Table 2. In control group, mean birth weight of babies was higher $(2853 \pm 320 \mathrm{gms})$ in comparison to PIH group (2516 $\pm 385 \mathrm{gms})$. This difference was found statistically significant. ( $p$ value 0.003). The mean weight of placenta ( $474 \pm 58$ grams) was higher among control group in comparison to PIH group ( $420 \pm 61$ grams).
This difference was statistically significant. (p $0.001)$ The mean fetoplacental weight ratio $(6.14 \pm$ 0.503 ) was higher among PIH group in comparison to control group $(6.03 \pm 0.409)$. This difference was statistically insignificant. $(\mathrm{p}>0.05)$ 
Table 3: Placental morphology in study group

\begin{tabular}{|l|c|c|c|c|c|}
\hline \multirow{2}{*}{ Placental Morphology } & \multicolumn{2}{|c|}{$\begin{array}{c}\text { Control } \\
(\mathbf{n = 3 0 )}\end{array}$} & \multicolumn{2}{c|}{$\begin{array}{c}\text { PIH } \\
(\mathbf{n = 3 0})\end{array}$} & \\
\cline { 2 - 5 } & No. & $\mathbf{\%}$ & No. & $\mathbf{\%}$ & \\
\hline Infarction (gross) & 1 & 3.3 & 20 & 66.7 & 0.001 \\
\hline Calcification (gross) & 11 & 36.7 & 26 & 86.7 & 0.001 \\
\hline Hyalinised area /10 lpf & 3 & 10.0 & 15 & 50.0 & 0.003 \\
\hline Medial coat proliferation/ 10 lpf & 2 & 6.7 & 23 & 76.7 & 0.001 \\
\hline Intervillous hemorrhage & 3 & 10.0 & 22 & 73.3 & 0.003 \\
\hline Decreased Villous Vascularity & 0 & 0 & 22 & 73.3 & 0.001 \\
\hline
\end{tabular}

On analyzing gross and microscopic features of the placentae, there was significant association between presence of gross infarction, calcification among control group and cases. Microscopic features also showed significant differences. (Table 3) Comparison of microscopic features of placenta among the PIH and control group were as shown in Table 4. Comparison of placental morphology among study participants was as shown in table 5.

Table 4: Distribution of study subjects according to microscopic features of placenta

\begin{tabular}{|c|c|c|c|c|}
\hline \multirow[t]{2}{*}{ Microscopic features } & \multicolumn{2}{|c|}{$\begin{array}{c}\begin{array}{c}\text { Control } \\
(\mathbf{n}=\mathbf{3 0})\end{array} \\
\end{array}$} & \multicolumn{2}{|c|}{$\begin{array}{c}\text { PIH } \\
(\mathbf{n}=\mathbf{3 0})\end{array}$} \\
\hline & No. & $\%$ & No. & $\%$ \\
\hline \multicolumn{5}{|c|}{ No. of Syncytial Knots formation per 100 villi } \\
\hline $0-30$ & 18 & 60 & 0 & 0 \\
\hline $31-60$ & 12 & 40 & 9 & 30 \\
\hline $61-90$ & 0 & 0 & 18 & 60 \\
\hline $91-120$ & 0 & 0 & 03 & 10 \\
\hline \multicolumn{5}{|c|}{ No. of areas of fibrinoid necrosis / 100 villi } \\
\hline $01-05$ & 27 & 90 & 0 & 0 \\
\hline $06-10$ & 3 & 10 & 14 & 46.7 \\
\hline $11-15$ & 0 & 0 & 8 & 26.7 \\
\hline $16-20$ & 0 & 0 & 7 & 23.3 \\
\hline $21-25$ & 0 & 0 & 1 & 3.3 \\
\hline \multicolumn{5}{|c|}{ No. of areas of cytotrophoblastic proliferation } \\
\hline $01-05$ & 23 & 76.7 & 0 & 0 \\
\hline $06-10$ & 7 & 23.3 & 4 & 13.3 \\
\hline $11-15$ & 0 & 0 & 10 & 33.3 \\
\hline $16-20$ & 0 & 0 & 11 & 36.7 \\
\hline $21-25$ & 0 & 0 & 5 & 16.7 \\
\hline \multicolumn{5}{|c|}{ No. of calcified areas/10 lpf } \\
\hline 0 & 19 & 63.3 & 3 & 10 \\
\hline 1 & 9 & 30 & 4 & 13.3 \\
\hline 2 & 2 & 6.7 & 13 & 43.4 \\
\hline 3 & 0 & 0 & 5 & 16.7 \\
\hline 4 & 0 & 0 & 4 & 13.3 \\
\hline 5 & 0 & 0 & 1 & 3.3 \\
\hline
\end{tabular}

Table 5: Comparison of placental morphology among study participants (n=60)

\begin{tabular}{|c|c|c|c|c|c|}
\hline Placental morphology & Group & $\mathbf{n}$ & Mean & Std. deviation & P value \\
\hline \multirow{2}{*}{ Syncitial knots /100 villi } & Control & 30 & 29.3 & 7.84395 & \multirow{2}{*}{0.001} \\
\hline & PIH & 30 & 72.6333 & 14.8359 & \\
\hline \multirow{2}{*}{ Fibrinoid necrosis /100 villi } & Control & 30 & 3.4333 & 1.56873 & \multirow{2}{*}{0.001} \\
\hline & PIH & 30 & 12.3333 & 4.39697 & \\
\hline \multirow{2}{*}{ Hyalinized villi / 10 lpf } & Control & 30 & 1 & 0.94686 & \multirow{2}{*}{0.0003} \\
\hline & $\mathrm{PIH}$ & 30 & 6.9333 & 2.50425 & \\
\hline \multirow{2}{*}{$\begin{array}{l}\text { Cytotrophoblastic } \\
\text { Proliferation / } 100 \text { villi }\end{array}$} & Control & 30 & 3.6667 & 2.57753 & \multirow{2}{*}{0.001} \\
\hline & PIH & 30 & 16.2 & 4.27019 & \\
\hline \multirow{2}{*}{ Calcified areas / $10 \mathrm{lpf}$} & Control & 30 & 0.43 & 0.626 & \multirow{2}{*}{0.001} \\
\hline & PIH & 30 & 2.2 & 1.242 & \\
\hline
\end{tabular}




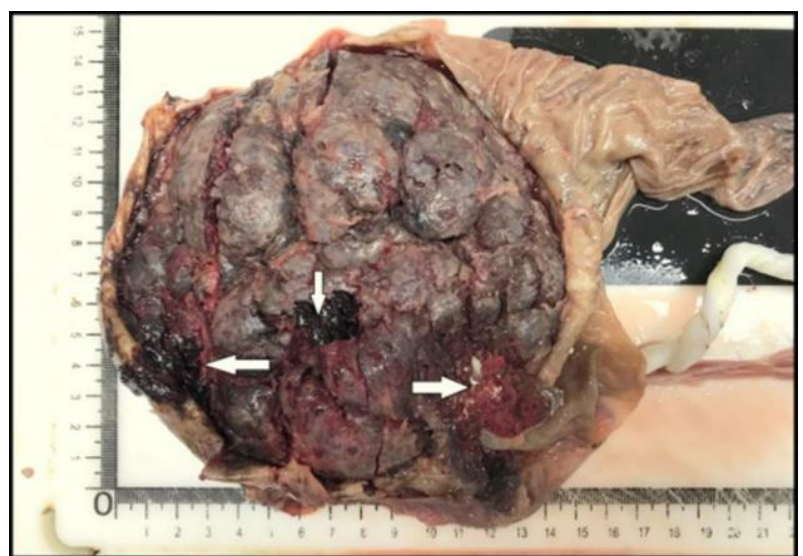

Fig. 1: Gross picture of PIH placenta showing haemorrhage and necrosis (white arrows)

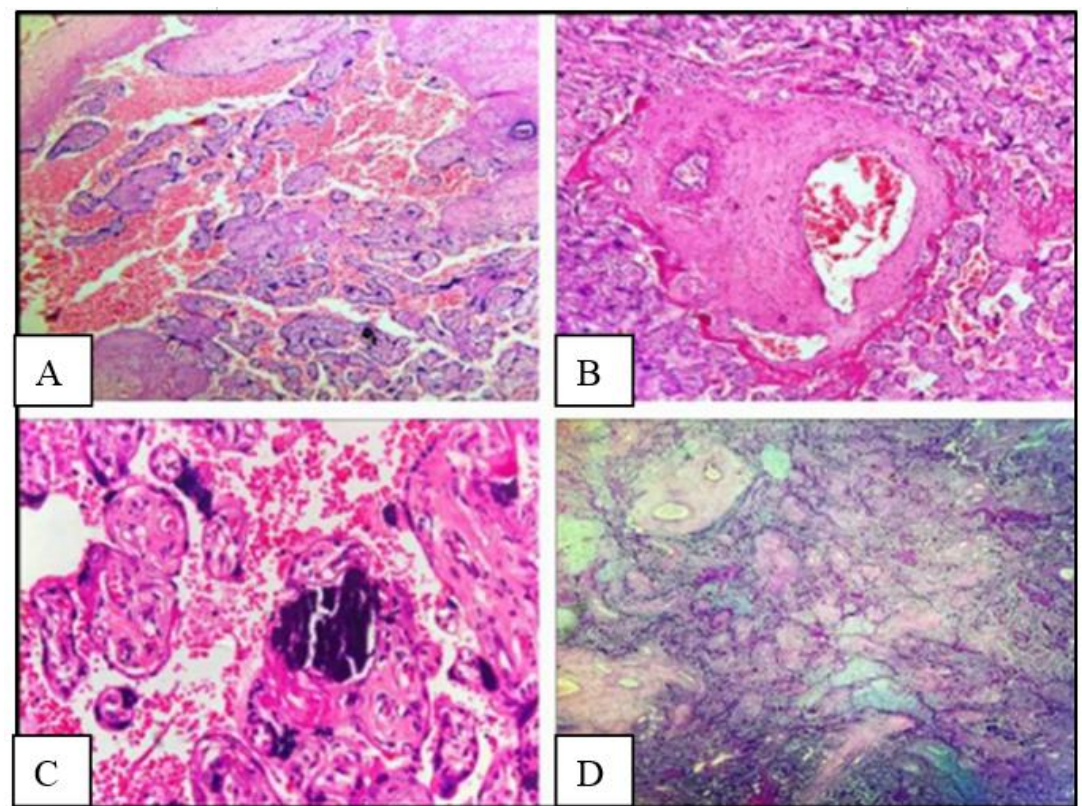

Fig. 2: Photomicrograph showing; A). Intervillous haemorrhage (H \& E, 100X); B). Vascular medial coat proliferation (H \& E, 100X); C). Calcification (H \& E, 400X); D). Areas of infarction (H \& E, 100X).

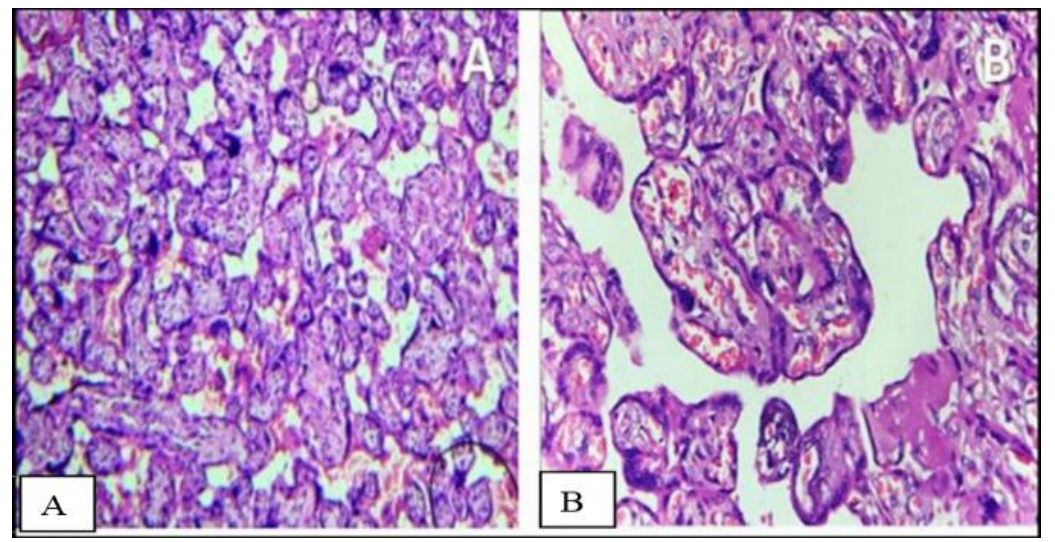

Fig. 3: Photomicrograph showing; A). Decreased villous vascularity in PIH (H \& E, 100X); B). Syncitial knots in pre-eclamptic placenta $(\mathrm{H} \& \mathrm{E}, 400 \mathrm{X})$ 

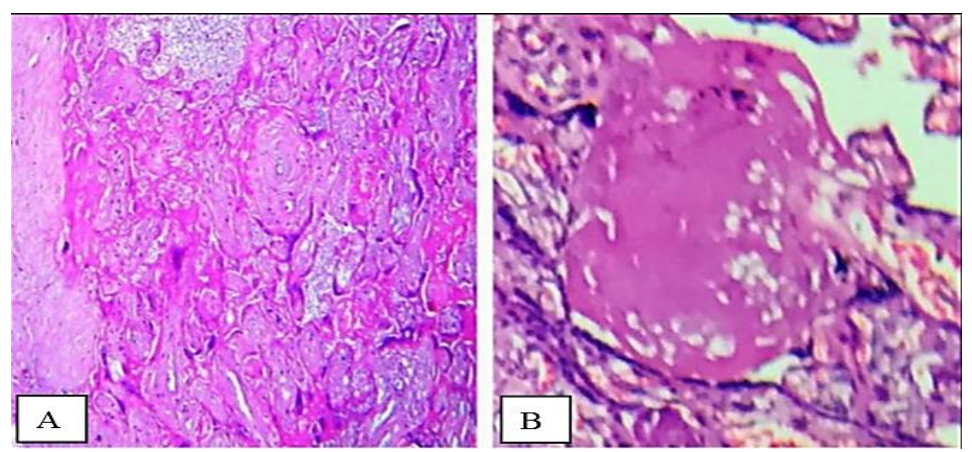

Fig. 4: Photomicrograph showing; A). Extensive fibrinoid necrosis (arrow) (H \& E, 100X); B). Fibrinoid necrosis involving entire villous. ( $\mathrm{H} \& \mathrm{E}, 400 \mathrm{X})$

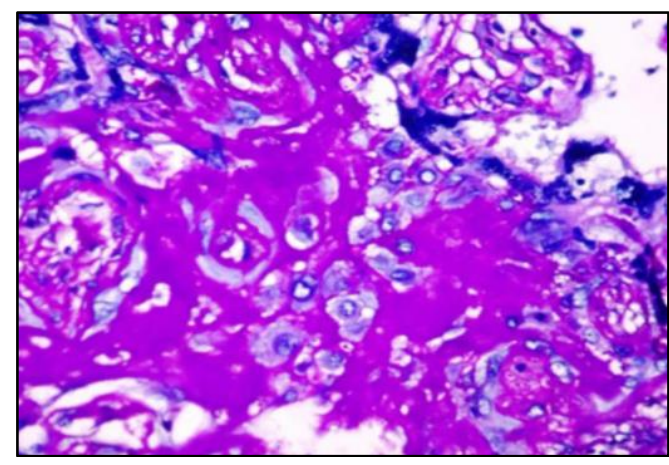

Fig. 5: Photomicrograph of intervillous fibrin deposition. (Magenta) (PAS, 400X)

\section{Discussion}

In the present study, mean birth weight of babies was higher (2853 $\pm 320 \mathrm{gms})$ in control group compared to $\mathrm{PIH}$ group $(2516 \pm 385 \mathrm{gms})$. This difference was found statistically significant. ( $\mathrm{p}$ value 0.003 ). In the study conducted by Shevade et $\mathrm{al},{ }^{8}$ the mean foetal weight was $2.1 \mathrm{~kg}$ and $2.8 \mathrm{~kg}$ in PIH group and control group respectively. S Kishwara et al, ${ }^{9}$ Boyd and Scott ${ }^{10}$ (1985), Mayhew et al. (2003) $)^{11}$ Barton et al. (2001) ${ }^{12}$ observed that the mean birth weight of the neonate was significantly lower in the group with preeclampsia than that of control group. Odegard et al. (2000) ${ }^{13}$ found that preeclampsia was associated with a $5 \%$ reduction in birth weight.

The mean fetoplacental weight ratio $(6.14 \pm 0.503)$ was higher among preeclampsia group women in comparison to control group $(6.03 \pm 0.409)$. However this, difference was statistically insignificant. Majumdar et $\mathrm{al}^{14}$ found fetoplacental weight ratio of 6.23:1, Nag U et al ${ }^{15}$ found 6.02:1, Deepalaxmi Salmani et $\mathrm{al}^{16}$ found 6.35:1 in PIH group while Majumdar et $\mathrm{al}^{14}$ found fetoplacental weight ratio of 5.89:1, Nag U et $\mathrm{al}^{15}$ found 5.94:1, Deepalaxmi Salmani et al ${ }^{16}$ found 5.72:1 in control group.

There was significant difference between presence of infarction in control group and PIH group ( $p$ value 0.001). (Fig. 1, 2) These findings were similar with the findings of Wentworth et al ${ }^{17}$ Salvatre et al ${ }^{18}$ Infarction occurs due to thrombotic occlusion of maternal uteroplacental blood vessels and is seen in pregnancies complicated by PIH. There is worsening of uteroplacental ischemia resulting in high incidence of foetal hypoxia, intrauterine growth retardation and foetal death in PIH as stated by Raghvendra et al. ${ }^{19}$

Mean number of syncitial knots was $72.6 \pm 14.8$ in PIH group while it was $29.3 \pm 7.8$ in control group which was found significant (0.001). Fig. 3) It was higher in PIH group compared to control group. Similar results have been observed by Saeed et $\mathrm{al},{ }^{20}$ Sharma et $\mathrm{al}^{21}$ Pasricha et al, ${ }^{22}$ Dhabhai et $\mathrm{al}^{23}$ and Nafees et al. ${ }^{24}$ They found higher number of syncytial knots in preeclamptic placenta as compared to control placenta. Khalid et al, ${ }^{25}$ Narasimha et $\mathrm{al}^{26}$ and Tomas et $\mathrm{al}^{27}$ have also reported the similar findings.

There was statistically significant association between PIH and presence of hyalinised area. ( $p$ value 0.0003). (Fig. 4,5) Various workers like Costa et al, ${ }^{28}$ Motwani et $\mathrm{al}^{29}$ and Salgado et $\mathrm{al}^{30}$ have previously demonstrated hyalinised villi in preeclamptic placenta.

The mean number of cytotrophoblastic proliferation was $16.2 \pm 4.27$ in PIH group while it was $3.6 \pm 2.57$ in control group. Our study showed significantly increased cytotrophoblast proliferation in preeclamptic placenta as compared to control placenta. Jones et $\mathrm{al}^{31}$ found significant increase in number of cytotrophoblast cells in preeclamptic placenta. Narasimha et al, ${ }^{26}$ Arnholdt et al, ${ }^{32}$ Motwani et a, $1^{29}$ Nafees et $a l,{ }^{24}$ Maqueo et $\mathrm{al}^{33}$ and also found similar results.

There was statistically significant association between PIH and decreased villous vascularity. (Fig. 3) ( $p$ value 0.001). Majumdar Set al, ${ }^{14}$ Motwani et $\mathrm{al}^{29}$ and Narasimha et al $^{26}$ reported reduced villous vascularity in preeclamptic placenta as compared to control placenta. Saleh et $\mathrm{al}^{34}$ observed that villi of preeclamptic placenta showed condensed villous connective tissue core and regression of villous capillaries upto complete disappearance.

\section{Conclusion}

It is concluded from the present study that there was statistically significant difference between mean birth weight of the babies and mean placental weight in control group and PIH group. It also revealed striking villous lesions like increased syncytial knots, 
cytotrophoblastic cell proliferation, villous stromal fibrosis and fibrinoid necrosis in placenta from preeclampsia cases as compared to placenta from normal term pregnancy. Thus, it can be concluded that preeclampsia has adverse effect on morphology of placenta and consequently affects the foetal outcome.

\section{References}

1. J.C. Haulth, M.G. Ewell, R.J. Levine et al. Pregnancy outcomes in healthy nulliparous who developed hypertension. Obs \& gynecol. 2000;95(1):24-28.

2. Ahmed Maimoona, Daver Pekhag, Rekha G. Study of placental changes in pregnancy induced hypertension. International journal of reproduction, contraception, obstetrics \& gynaecology. 2013;2(4):525-527.

3. Naeye RL, Friedman EA. Causes of perinatal death associated with gestational hypertension and proteinuria. Am J Obst and Gynaecol. 1979;133:8-11.

4. Brown JCM, Veall N. The maternal blood flow in normotensive \& hypertensive women. Jr obst \& gyaenecol of British Empire. 1953;60:141-7.

5. Landsmon R, Douglas RG Holze E. The bulbar conjunctival vascular bed in toxaemias of pregnancies. Am J obst. \& Gyaenecol. 1954;68:170-72.

6. Roberts DJ, Post MD. The placenta in pre-eclampsia and intrauterine growth restriction. Journal of Clinical Pathology. 2008;61(12):1254-60.

7. Dahlstrom B, Romundstad P, Oian P, Vatten LJ, Eskild A. Placenta weight in preeclampsia. Acta Obstetricia et Gynecologica Scandinavica. 2008;87(6):608-11.

8. Sapna Shevade, Vasanti Arole, Vaishaly Bharambe, Vaishali Paranjape. Placental Morphology and Foetal Outcome in Preeclampsia And Normotensive Pregnancies. IOSR Journal of Dental and Medical Sciences (IOSR-JDMS). 2015;14(4):11-5.

9. S Kishwara, S Tanira, E Omar, F Wazed, S Ara. Effects of Preeclampsia on Perinatal Outcome- A Study Done in the Specialized Urban Hospital Set Up in Bangladesh. Bangladesh Medical Journal. 2011;40(1):33-6.

10. Boyd PA, Scott A. Quantitative structural studies on human placentae associated with preeclampsia, essential hypertension and intrauterine growth retardation. $\mathrm{Br} \mathrm{J}$ Obstet Gynaecol. 1985;92:714-21.

11. Mayhew TM, Ohadike C, Baker PN, Crocker IP, Mitchell $\mathrm{C}$, Ong SS. Stereological investigation of placental morphology in pregnancies complicated by preeclampsia with and without intrauterine growth restriction. Placenta. 2003;24:219-26.

12. Barton JR. O'Brien JM, Bergauer NK, Jacques DL, Sibai BM. Mild gestational hypertension remote from term: progression and outcome. Am J Obstet Gynecol. 2001;184(5):979-83.

13. Odegård RA, Vatten LJ, Nilsen ST, Salvesen KA, Austgulen R. Preeclampsia and foetal growth. Obstet Gynecol. 2000;96(6):950-5.

14. Majumdar S, Dasgupta H, Bhattacharya K, Bhattacharya A. A Study of Placenta in Normal and Hypertensive Pregnancies. J Anat Soc India. 2005;54(2):1-9.

15. Nag U, Chakravarthy VK, Rao DR. Morphological changes in placenta of hypertensive pregnant women. JRRMS. 2013;3(2):1-4.

16. Deepalaxmi Salmani et al. Study of structural changes in placenta in pregnancy-induced hypertension. $J$ Nat Sci Biol Med. 2014;5(2):352-55.

17. Wentworth. Placental infarctions and toxaemia of pregnancy. Am J Obstet Gynecol. 1967;99(3):318-25.
18. Salvatre. The placenta in acute toxaemia. Am J Obstet Gynecol. 1968;102(3):347-53.

19. Raghvendra AY, Vinay KV, Veena Pai. A study of placental weight and foetal outcome in different grades of pregnancy induced hypertension. Int $J$ Anat Res. 2012;2(4):625-9.

20. Saeed I, Iqbal I, Rehman S, Qamar K, Butt SA, Shaukat S. Histomorphological Changes in Placentae of PreEclamptic Mothers with Reference to Vasculosyncytial Membrane Thickness and Syncytial Knot formation. Journal of Rawalpindi Medical College (JRMC). 2012;16(1):51-4.

21. Sharma M, Kumar R, Dhingra R. An immunohistochemical study of the syncytial knots in the preeclamptic placentae. IJPRBS 2012;1(44):228-39.

22. Pasricha N, Nagar A, Gupta A. Histological changes in placentae in pregnancies complicated by preeclampsia and eclampsia and corelation with foetal outcome. International Journal of Pharma and Bio Sciences. 2012;3(2):551-60.

23. Dhabhai P, Gupta G, Bapna N. Histology of human placenta in normal and pregnancy induced hypertension. International Journal of Pharmaceutical science Invention. 2013;2(11):30-5.

24. Nafees H, JainS, Khare S, Khare A, Kaansal R. Histopathological Study of Placental Villi in PreEclampsia:a Quantitative Study. Journal of Anatomical Society of India. 2012;61(2):159-62.

25. Khalid ME, Ali ME, Ali KZ. Full-term birth weight and placental morphology at high and low altitude. Int $J$ Gynaecol Obstet. 1997;57:259-65.

26. Narasimha A, Vasudeva DS. Spectrum of changes in placenta in toxemia of pregnancy. Indian J Pathol Microbiol. 2011;54:15-20.

27. Tomas SZ, Prusac IK, Roje D, Tadin I. Trophoblast apoptosis in placentae from pregnancies complicated by preeclampsia. Gynecol Obstet Invest. 2011;71:250-5.

28. Costa AM, Maximiano EB, Prtari E, Jesus NR, Levy RA. Contractile cells and fibrillin-1 distribution is disturbrd on terminal villi of placentae from patients with preeclampsia and systemic lupus erythmatosis. Placenta. 2006;2:234-43.

29. Motwani R, Sontakke Y, Goyal M. Effects of pregnancy induced hypertension on human placenta. Journal of Evolution of Medical and Dental Sciences. 2013;2(3):6275-82.

30. Salgado SS, Salgado MK. Structural changes in preeclamptic and eclamptic placentae--an ultrastructural study. J Coll Physicians Surg Pak. 2011;21(8):482-6.

31. Jones CJ, Fox H. An ultrastructural and ultrahistochemical study of human placenta in maternal preeclampsia. Placenta 1980;1:71-6.

32. Arnholdt H, Meisel F, Fandrey K, Löhrs U. Proliferation of villous trophoblast of the human placenta in normal and abnormal pregnancies. Virchows Arch B Cell Pathol Incl Mol Pathol. 1991;60(6):365-72.

33. Maqueo M, Chavezazuela J, Dosaldelavega M. Placental Pathology in Eclampsia and Preeclampsia. Obstet Gynecol. 1964;24:350-6.

34. Saleh RA, Dkhil MA. Structural Changes of Placenta in Preeclamptic Patients: Light and Electron Microscopic Study. Turk J Med Sci. 2008;38(3):219-25.

How to cite this article: Gore CR, Pandey A, Shetty A, Rao R, Paranjape S. A study on histopathological changes in placenta in pre-eclampsia/eclampsia: A casecontrol study in tertiary care centre, western India. Ind J Pathol Oncol, 2018;5(3):385-390. 